\title{
Expanding the Legal Vocabulary: The Challenge Posed by the Deconstruction and Defense of Law
}

\author{
Christine A. Desan Husson
}

\section{INTRODUCTION}

Critical Legal Studies (C.L.S.) launched an offensive against our traditional notions of legal theory and interpretation that has mounted to an onslaught. ${ }^{1}$ At the same time, the credibility of the movement has slipped. ${ }^{2}$ The combination appears paradoxical, but its cause is straightforward: While the C.L.S. critique is penetrating, ${ }^{3}$ the positive program offered by Critical scholars has been less convincing." The movement's success has

1. A recent bibliography of "C.L.S.-type works" compiled by Karl Klare and Duncan Kennedy lists over 180 authors and more than 500 articles and books. Kennedy \& Klare, A Bibliography of Critical Legal Studies, 94 YAle L.J. 461, 462 (1984).

2. Phillip Johnson expresses a popular sentiment, albeit antagonistically, when he asks whether the Critical Legal Studies movement is a "Peter Pan syndrome," and concludes that its members are products of the 1960's who are "[p]laying with Marxism" because they want to be radicals but have not learned how. Johnson, Do You Sincerely Want To Be Radical?, 36 STAN. L. REv. 247, 248, 291 (1984). See also Schwartz, With Gun and Camera Through Darkest CLS-Land, 36 STAN. L. REv. 413, 421 (1984) (C.L.S. fails to present "credible left" critique).

3. The deconstructive enterprise of C.L.S. has been exhaustively argued for and against; this Note does not attempt to reproduce that debate. For strong presentations of the deconstructionist critique, see Gordon, Critical Legal Histories, 36 Stan. L. Rev. 57 (1984); Kelman, Trashing, 36 Stan. L. Rev. 293 (1984); Unger, The Critical Legal Studies Movement, 96 HARv. L. REv. 561 (1983). For responses critical of the deconstruction, see Fiss, Objectivity and Interpretation, 34 STAN. L. REv. 739 (1982); Johnson, supra note 2, at 247; Sparer, Fundamental Human Rights, Legal Entitlements, and the Social Struggle: A Friendly Critique of the Critical Legal Studies Movement, 36 Stan. L. Rev. 509 (1984). Critical deconstruction is, of course, far from the first critique to target claims of formalism, determinism, neutrality or objectivity in legal theory. Such criticism has been articulated for many years by Legal Realists and other scholars. For the Realist approach, see, e.g., J. Frank, LAw AND THE Modern Mind (Anchor Books ed. 1963); Cohen, Transcendental Nonsense and the Functional Approach, 35 Colum. L. REv. 809 (1935); Llewellyn, Some Realism about Realism, 44 Harv. L. Rev. 1222 (1931). For a different perspective, see, e.g., R. SEIDMAN, The State, Law, ANd Development 379, 464 (1978) (analyzing law as instrument of state). The Critical scholars have, however, distinguished themselves by pressing their criticisms with special intransigence through an urgent and confrontational presentation.

4. The frequent charge that C.L.S. does not even have a positive program is neither a strong claim nor an accurate one. First, as William Simon correctly points out, Critical scholars have as much right, one might say duty, as social scientists do to describe the system they perceive. Simon, Visions of Practice in Legal Thought, 36 STAN. L. REv. 469, 502 (1984). Second, several positive programs have in fact been suggested. Duncan Kennedy and Joseph Singer sincerely believe, like their philosophical counterpart, Richard Rorty, that a world in which we give up trying to construct abstractions or acquire "objective" knowledge would be a positive development. See Gabel \& Kennedy, Roll Over, Beethoven, 36 STAN. L. Rev. 1, 36-55 (1984); Singer, The Players and the Cards: Nihilism and Legal Theory, 94 YAle L. J. 1 (1984); R. RORTY, Philosophy AND the MrRRor of 
come in deconstructing the objective and formal quality of our law, and in piercing the myth of our autonomy as legal agents. ${ }^{\circ}$ Yet its prescriptive faith in our human capacity to create new and better societies when freed from the disempowering mystification of our present system seems to many to be naive, vague, or ill-formed. ${ }^{6}$

Skepticism about the Critical conclusion may obscure revelations made during Critical deconstruction because C.L.S. itself has never persuasively incorporated into its vision for the future the lessons it has exposed from our past. Critical scholars have reacted against the image that significantly informs our present legal and social structures-an image of atomized individuals linked in their relations by some invisible social contract or mega-marketplace. ${ }^{7}$ The Critical movement and those who admit its criticisms as significant must now more fully examine the alternative-the possibility of subjects who create their own contexts interdependently and endlessly. In analyzing the alternative, the group must also more fully face the self it finds in each context, a self who insists on objectifying the constructs it creates.

\section{Deconstruction of the Legal System and its Subject}

The pattern of the Critical enterprise is by now familiar, though the claim that it is one bifurcated in both sequence and success (penetrating critique followed by less persuasive prescription) requires amplification. G.L.S. begins its critique strongly, incisively deconstructing or "trashing" our allegedly cohesive legal system by demonstrating its inconsistencies and exploiting its contradictions. ${ }^{8}$ The exercise aims to expose law as a human construct whose partisan nature is masked by objectification, or "sanctification," the elevation of subjective understandings to the status of

NATURE (1979). Unger has suggested his own program through which humans could develop their personal and political potential. See Unger, supra note 3. Other Critical scholars have suggested more specific reform proposals. See Kelman, supra note 3, at 299-303 (proposals surveyed).

5. See, e.g., Heller, Structuralism and Critique, 36 Stan. L. REv. 127 (1984) (comparing conception of individual agent in liberalism with counterpart in structuralist worldviews); Simon, supra note 4 (refuting notion of lawyer as independent agent); see also Dalton, An Essay in the Deconstruction of Contract Doctrine 94 YALE L. J. 997, 1006-09 (1985) (identifying as unsubstantiated liberal claim to mediate human relationships clearly). The unsatisfactory nature of current conceptions of the individual has been a strong theme in Roberto Unger's work. See Unger, supra note 3, at 584-88; R. UNGer, KNowledge and Politics 29-62, 191-96 (1975); R. Unger, Passion: AN Essay on Personaltry (1984); see infra note 16.

6. See, e.g., Johnson, supra note 2 , at $249,256-65,281-91$.

7. Id. at 256 (stating image from liberal perspective); Unger, supra note 3, at 567-70 (stating image from Critical perspective).

8. "Trashing" is deconstruction in an irreverent mood, as evinced in the definition of the operation that follows: "Take specific arguments very seriously in their own terms; discover they are actually foolish ([tragi]-comic); and then look for some (external observer's) order (not the germ of truth) in the internally contradictory, incoherent chaos we've exposed." Kelman, supra note 3, at 293 (emphasis in original). 
objective standards. ${ }^{9}$ Through objectification, the law achieves an illusory but intimidating authority. It appears to be the embodiment of a neutral or natural ethic, a "given" structure, rather than a contingent construction. The hierarchies that the law guards, institutionalized in our society, likewise appear to be natural and necessary, rather than the malleable creations of men $^{10}$ that they actually are. ${ }^{11}$

Critical scholars identify the legal structure objectified and protected by this sanctifying operation to be liberal jurisprudence-a jurisprudence that sets as an aspirational ideal a society of free and equal individuals. ${ }^{12}$ In a move that makes their deconstructive enterprise complete, Critical scholars blast the assumption behind the ideal itself: They reject the liberal definition of the human being as an independent, self-defining agent. ${ }^{13}$ That is, they dismiss as an unsuccessful apologist for the present system its central actor-the autonomous subject whose natural habitat is one of freedom of contract and property rights. ${ }^{14}$

It is entirely possible to justify the dissection of the legal structure and its architect as an exercise in description, a social science function mandated by that discipline's drive to analyze behavior. Most Critical scholars however, present their action as a social service as well, because there are normative implications of the exercise they would like to draw out. ${ }^{15}$ First, in revealing the contingency of our present system by refuting its objectification, they hope to empower people to create new and fairer soci-

9. Unger, supra note 3 , at 571 .

10. The significance of gender here is a point well made in feminist legal theory. See, e.g., MacKinnon, Feminism, Marxism, Method, and the State: Toward Feminist Jurisprudence, 8 SIGNs: J WOMEN CuLTURE \& SOC'Y 635, 636, 644-45 (1983).

11. See, e.g., Gordon, supra note 3, at 109-13.

12. Political scientist David Apter describes the "classic liberal picture" of a political community:

Behaviorally, the . . . model consists of units that possess two capacities: the ability to reason and the ability to know self-interest. . . . Structurally, the system must allow maximum opportunity for the exercise of rationality and the pursuit of self-interest.: Hence the emphasis is on a framework that will prevent coercion and provide limited government. The usual realization of this need is a system of representative government with checks and balances designed to prevent tyranny. Normatively, such a system takes certain fundamental proprieties as given.

D. Apter, The Politics of Modernization 28 (1965) (emphasis in original). This Note will assume a definition of liberal jurisprudence that accords with such a model. See, e.g., Heller, supra note 5 , at $132 \mathrm{n} .12$. Such jurisprudence has often been linked to market and contract forms of social organization, according to which the most sophisticated defenses and elaborations of liberal political theory have been made. See, e.g., F. HAYEK, The CoNSTITUTION OF LIBERTY (1960) (free market model); R. Nozick, ANarchy, State, and Utopia (1974) (free market model); J. Rawls, A TheORY OF JUSTICE (1971) (social contract model). For additional definitions of liberal jurisprudence forwarded recently, see e.g., Gordon, supra note 3, at 59-65; Johnson, supra note 2, at 256; Sparer, supra note 3 , at 516-22.

13. See supra note 5 .

14. See, e.g., Dalton, supra note 5, at 1006-07, 1113-14 and passim (deconstructing contract doctrine); Kennedy, The Structure of Blackstone's Commentaries, 28 Buffalo L. REv. 205 (1979) (deconstructing Blackstone's scheme of legal classification).

15. See, e.g., Simon, supra note 4 , at 506-07. 
etal arrangements. ${ }^{18}$ And, having identified as ideology our legal and social autonomy, they advocate arrangements oriented towards beings who are fundamentally interdependent rather than individuals seeded in a competitive hierarchy. ${ }^{17}$

The aspiration sounds appealing. However, it is not quite convincing. The interdependent subject with the creative potential remains a vague, somewhat furtive hero hidden within the liberal subject. When the inner figure is revealed, Critical investigation fails to explicate adequately an attribute just as outstanding as the figure's creative ability-its persistence in confining itself within the legal structures it creates. ${ }^{18}$ Although there are lessons to be drawn from the Critical dismantling of our legal system, that structure has not disappeared for all its intellectual devastation. Liberalism presents not only a specific ideology, but also a striking example of a system objectified by its society. Clearly, the phenomenon of objectification cannot simply be dismissed, ${ }^{10}$ nor does a faith in our ability to transcend the structures it defines appear to be spreading. ${ }^{20}$

The observations above set an agenda for those who would admit and seek to incorporate the insights generated in the debate over liberal legality. We must draw out, first, the implications of a subject who is an intersubjective creator ${ }^{21}$ rather than an autonomous agent. Subsequently, after admitting objectification to be an operation pervasively used to conceal the subjectivity of the social and legal structures we create, we need to investigate why objectification is so widely available as a mask and means of manipulation. That is, we must move beyond arguing the fact of objectification to addressing its motive as well. ${ }^{22}$ Until then we will remain with

16. According to Unger, as deconstruction demonstrates that there is not one necessary and natural legal structure, it also reveals a definition of the self in terms of its "power . . eternally to transcend the limited imaginative and social worlds that it constructs." Unger, supra note 3, at 587. See also Gabel \& Kennedy, supra note 4, at 32-33 (noting pacifying potential of rights doctrine); Simon, supra note 4, at 503-07 (advocating demystification as lawyerly function).

17. Unger is the Critical scholar who describes human interdependence most fully, giving it a deep psychological basis. His image of the self, torn between fear of and longing for the other, is developed in R. UNGER, PAssion, supra note 5 . Critical scholars advocate non-hierarchical social arrangements as ideal for such interdependent beings. See, e.g., Simon, supra note 4, at 485; Unger, supra note 3 , at 585 .

18. Objectification has been categorized most commonly by the Critical school as a problem rather than a human characteristic. It thus appears an obstacle that can be resolved, given the correct solution. The antidote most frequently suggested within the school is the institution of non-hierarchical social arrangements, on the theory that objectification occurs because the powerful pacify those below them with such "hallucination[s]" as rights-based structures. Gabel \& Kennedy, supra note 4, at 33-34. Recognizing that objectification is not only imposed but continually generated from within, Kennedy swears off abstract characterization as a whole, positing freedom to be only and ever in the interstices of structures. Id. at 53. Neither conclusion is fully responsive to the continuing force exerted by objectification.

19. See infra note 24.

20. See supra note 16.

21. See infra text accompanying note 28 .

22. See supra note 18. 
theories and aspirations that are neither sociologically realistic nor psychologically responsive.

\section{INTERSUBjECTIVITY AND OBJECTIFICATION}

C.L.S. has not been alone in questioning the autonomy of the individual, ${ }^{23}$ nor in confronting its objectifying tendency. ${ }^{24}$ In fact, the debate in the legal arena appears fledgling relative to inquiries into intersubjectivity and objectification made in other fields. ${ }^{25}$ These non-legal theories, and the areas of conflict, agreement, and complementarity that connect them, contain noteworthy implications for our concept of law and our role in shaping it. Such is the hypothesis that guides the following exploration into two different approaches to intersubjectivity and objectification (Section II) and that justifies the application to law of a composite generated by that exploration (Section III).

23. Two penetrating critiques of liberalism from a communitarian perspective are A. Macintyre, After Virtue (1981), and M. SANDel, Liberalism and the Limits of Justice (1982). For a proposal that attempts to move us beyond the perceived impasse of liberal individualism, see Cornell, Toward a Modern/Postmodern Reconstruction of Ethics, 133 U. PA. L. REv. 291 (1985).

24. The deconstructionist legal argument is closely paralleled by a philosophical form. Richard Rorty, a noted deconstructionist philosopher, is also engaged in demonstrating to us that our quest for objective knowledge is misguided. Rorty points first to the failure of the Enlightenment Project-the attempt made during the last three centuries to find objective truth (i.e., final answers) by applying to areas including morality, law, and history the empirical approach that seemed to ensure success for science. Rorty then asserts even scientific knowledge to be relative by following the line of argument developed by Thomas Kuhn: Our apparently stable scientific knowledge becomes just the latest in a series of theories, simply the story about reality that happens to be the one most currently accepted.

For both Unger and Rorty, the human is singular for his or her tremendous creative potential. Unger identifies the person as "a being whose most remarkable quality is precisely the power to overcome and revise . . . every social or mental structure in which he moves," Unger, supra note 3, at 585, while Rorty characterizes him or her to be most fundamentally the generator of an infinite number of descriptions that are varied, interesting, and ultimately incommensurable. R. RORTY, supra note 4, at 378. For Rorty, the belief in objective knowledge-the declaration that one model of reality (or one legal system) correctly mirrors nature-is a most dangerous mistake. Such a belief silences the diversity of discourse that is distinctive to humankind. Thus we should recognize and reject our search for objectivity, dismissing it as an unnecessary and harmful folly. Id. at 315-94. See also Singer, supra note 4, for an application of Rorty's argument to legal theory.

25. Heller, supra note 5, reviews issues in the wide-ranging debates occurring in philosophy and linguistics. Controversy is also full-blown in the fields of sociology, e.g., P. WINCH, The IDEA of A Social Science and its Relation to Philosophy (1958) (contending that sociologists must grasp unreflective understanding of community members before making detached evaluations), literary criticism, e.g., S. Fish, Is There A TEXT IN ThIS Class? (1980) (arguing that understanding and socially-mediated interpretation occur simultaneously), political science, e.g., H. ARENDT, THE Human CondrTion (1958) (asserting political (public) interaction as condition for individual freedom), and even the natural sciences, e.g., T. KUHN, STRUCTURE of ScIENTrFic REvolurions (enlarged $2 d$ ed. 1970) (describing scientific "knowledge" to be defined by socially-dominant paradigm). 


\section{A. Reconstruction of the Subject}

\section{Establishing Intersubjectivity}

Studies of the self and its language have generated an increasing number of theories with a common theme-the depth and extent of human interdependence. One of the most compelling of these is Jurgen Habermas' theory of communicative action. ${ }^{26}$ The theory suggests that our interrelations determine not only the languages we speak but the very images of reality we adopt.

Habermas clears the ground for his model by dispelling our complacency about the way reality is organized. He attacks the subject/object dichotomy we conventionally assume, exploding it by arguing that there are not two but three dimensions to our world: the subjective, the objective, and the social. Habermas suggests that these three axes offer coordinates according to which we locate and thus are able to discriminate and categorize facts, norms, and experiences. ${ }^{27}$

Language offers the medium: Using it to negotiate descriptions of our situation with others, we arrive at definitions of reality that will be intersubjectively recognized and thus validated. That is, our interpretations of the world are formed through the cooperative process of "communicative action,"28 and are thus dependent in a fundamental way on the interpretations of our colleagues. Understanding, the crucial goal, is achieved as each communicant endlessly, though often unconsciously, recognizes and evaluates reasons for claims made by others, while asserting reasons for claims of his or her own. The primacy of reasoning gives the operation its name, "communicative rationality," and reveals the condition for its fully successful execution-an atmosphere free from coercion, in which the sole force is that of the better argument. This atmosphere, the "ideal speech situation," is profoundly important to the theory of communicative action, as both its basic presupposition and its central aspiration. ${ }^{30}$

Habermas establishes a model that expands our notion of the way peo-

26. This discussion will draw on Habermas' theory as it is most recently presented, in $J$. Habermas, The Theory of Communicative action: Reason and the Rationalization of SOCIETY (1981).

27. Id. at 70. This sketch, which obviously fails to do Habermas' theory justice, reviews material in the first section of his book. Id. at 1-141.

28. Id. at 86 .

29. Id. at 10 (term introduced), and 17-22 (term further explained).

30. Id. at 25. For an earlier formulation and an expert commentary, see, respectively, J. Habermas, Legrtimation Crisis 107-08 (1975); T. MCCarthy, The Critical Theory of JURGEN HABERmas 322-25 (1978). Such a speech situation is indeed an "ideal," one perhaps attainable only in degree: The less coercive are the conditions, the more will communicative rationality, and the understanding it achieves, flourish. The aspiration is not, however, separated from practice. Rather, the presupposition of ideal speech underlies all communication, since all speech is "oriented towards the idea of truth." Id. at 323 (quoting Habermas). 
ple construct society and its laws, developing the liberal free agent into a subject who defines his or her universe dependently and in dialogue, a communicator whose understanding correlates with the degree to which uncoerced exchange is possible. The route the model directs in practice, however, looks surprisingly familiar. It implies the creation of a truly open political process-the same ideal that underlies a theory of constitutional democracy like that of John Hart Ely. ${ }^{31}$. Both Habermas and Ely recognize the tremendous importance of participation in the communicatively-achieved structuring of society. Both therefore sanctify the right of all members of a political community to contribute to public decisions. ${ }^{32}$

Their theories share certain areas of underemphasis as well. Both Habermas' concentration on the free exercise of reason and choice and Ely's focus on open access to the political forum found a right of participation but inadequately explicate the responsibility of receptivity that is an essential ingredient of constructive exchange. ${ }^{33}$ And, stressing the process of decision-making, in politics or communication, ${ }^{34}$ neither author confronts the issue that towards whom we bear that responsibility requires a substantive answer. ${ }^{35}$ Even Habermas' stipulation that communicative

31. J. Ely, Democracy and Distrust (1980).

32. Drucilla Cornell, who uses Habermas' theory in developing a communitarian model, similarly emphasizes "participatory rights" and an ethic of involved citizenship. See Cornell, supra note 23, at $368,374$.

33. The point here is one of relative emphasis, for neither writer ignores the element. Ely is highly sensitive to the fact that "a voice and a vote" are devices insufficient to assure receptivity to the views of minorities and dissonant individuals in a representative democracy. J. ELY, supra note 31, at 135. He notes the existence of additional aids to such members: the guarantees offered by the Bill of Rights, the pluralistic structure of government, and the policy of "virtual representation" (the strategy of linking representatives' interests to those of their constituents). Id. at 79-84. However, because vuinerable members are precisely those "to whose needs and wishes elected officials have no apparent interest in attending" and those who may be unable to gain political leverage for "reasons that are in some sense discreditable," (e.g., prejudice), Ely depends most heavily on the courts to identify and protect such members by invalidating discriminatory legislation. Id. at 151, 152-53. Yet given his assertion elsewhere that the courts are likely to evidence a "systematic bias . . . in favor of the values of the upper-middle, professional class from which most judges and lawyers . . . are drawn" and the fact that even protective judicial acts may well leave minority members stymied as far as affirmative political action is concerned, the conclusion is less than satisfying. Id. at 59.

Habermas is obviously well aware that communication depends on receptivity, on listening to as well as contributing and choosing propositions. It is a premise of his theory of communicative action that communicants are, at a most basic level, oriented toward understanding one another, a mutually beneficial goal that can be achieved only cooperatively. J. HABERMAs, supra note 26, at 10-11. Yet beyond noting that prejudices amount to "coercion" in the ideal speech situation because they block the fair hearing of others' views, see supra note 30 and accompanying text, Habermas devotes little more discussion to receptivity. He thus appears to presume too easily the occurrence in practice of a quality clearly intrinsic to the operation of reason in theory. See infra text accompanying notes $41-48$, 85-101, for the responsibility of receptivity to which I contrast the listening element admittedly inherent to communicative action or a process theory of democracy.

34. See, e.g., J. ELY, supra note 31, at 74-75; J. Habermas, supra note 26, at 17-18, 249.

35. As Michael Walzer points out, theories of distributive justice often simply assume an established population and thus avoid having to answer what is actually "the first and most important distributive question" faced by a community-the selection of its members. M. WALZER, SPHERES OF Justice 31 (1983); of. J. ElY, supra note 31 , at 181 (process theory differentiated from theory 
action includes all humans as communicants, ${ }^{36}$ while satisfying in theory, accomplishes little as a directive in practice. Political conversation has in the past been comfortably confined to one race or one community; its insularity cannot be pierced by blunt assertion, but must be subjected to more focused argument.

If we are left with a concept of intersubjectivity curiously lacking in innovative implications, it is only because Habermas assumes too much of language, the medium of that intersubjectivity. A school of hermeneutics radically skeptical of the autonomous subject, forcefully represented by Martin Heidegger, uncovers the assumptions and unpacks them. ${ }^{37}$

\section{Developing Intersubjectivity}

In contributing insight into the selectivity of language, Heidegger helps to develop the difference between a model of intersubjectivity and one of autonomy. His idea can be stated with a simplicity that is somewhat misleading. Although it is the only way that humans can articulate reality, as language names things, it necessarily delimits them, restricting and in that sense distorting what is there to be discussed. ${ }^{38}$ The distortion occurs because language leaves out certain aspects of any subject. These aspects are not articulated as-and thus not granted the status of-reality. The case of vision presents a helpful analogy. In order to see anything, we must see from an angle. While the angle enables our vision, it also limits it, defining our view and determining its highlights. ${ }^{38}$

This understanding of language reaffirms the dismantling of the subject/object dichotomy with which our discussion of intersubjectivity started. Speech becomes a continual decision of what to reveal, thus also a selective interpretation that obscures what is not spoken. It is only as man loses sight of the dynamic nature of this phenomenon that he imagines the world to be "the Object," capable of full and accurate description by man, "the Subject."."

The Heideggerian notion represents a critical insight if Habermas is

focused on substantive merits, selection of members not discussed).

36. See J. Habermas, supra note 26, at 8; see also T. MCCARTHY, supra note 30, at 299 (quating Habermas).

37. The discussion here is drawn from Martin Heidegger's presentation of the ideas in AN INTRODuction TO METAPHXsics (1959). My understanding and expression of Heidegger's orientation have been significantly influenced by my exposure to Wilfrid Desan, who advances an approach similar in some respects. See W. Desan, The Planetary Man (1961).

38. See M. Heidegger, supra note 37, at 52-92, 156-58, 170-96; M. Heidegger, Existence AND BEING 313, 319 (Gatewood ed. 1949).

39. See, e.g., M. HeIdegger, supra note 37, at 104-05, 117. This image is also employed and explored by Desan. See W. DESAN, supra note 37, at 33-43 (emphasizing extent of human "angularity").

40. See M. Hemoggger, supra note 37, at 156-58, 188-206. I use the male referents here advisedly, because they are prominent terms in Heidegger's writing. 
correct that dialogue is the keystone to human understanding of the world. In maintaining that only by communication do humans interpret reality-separating out the objective, subjective, and social in order to organize their world into facts, experiences, and norms-Habermas assumes that language is capable of fully expressing the raw materials of that reality. ${ }^{41}$ In contrast, Heidegger argues that language is already a decision concerning meaning, a decision that distinguishes some things by casting others into shadow.

The qualification need not undermine Habermas' concept; it can strengthen it. Habermas, with his affirmative focus on our ability to achieve understanding through communication, inadequately explains the fact that our discourses are sometimes undeniably incommensurable. ${ }^{42}$ That is, translation-for Habermas the act that prototypically reveals rationality to be a universal operation ${ }^{43}$-is sometimes quite unable to replicate and convey meaning accurately.4 The Heideggerian notion of the selectivity of language resolves the problem. Incommensurability of human discourse is revealed to be a function of the fact that to speak (as to see) we must speak from an angle. We therefore express different or undeniably "incommensurable," if not unrelated, realities.

Recognizing the inherent selectivity of language extends the implications of an intersubjective model. ${ }^{45}$ First, receptivity becomes as important as speech. While before there was a reason to dialogue-to define our world-there is now a responsibility inherent in the dialogue-to realize and challenge the constant selectivity of our own interpretation. That is, while we had a motive to converse in order to validate our vision of the world, we now must recognize a need to listen to the visions of others, because there are whole dimensions of reality that we are unable to see. Even our capacity for critical reflection becomes dependent on the reality that we can learn from them, for our own information will always be incomplete. ${ }^{18}$ Thus truths discovered, whether by Dworkin's Hercules or

41. See T. MCCARTHY, supra note 30 , at 316 (reviewing Habermas' supposition that language is adequate to make "inner-natures transparent").

42. See supra note 24 ; infra note 44.

43. See J. Habermas, supra note 26, at 131-36.

44. Nor are the resulting incommensurabilities negligible. For Rorty, they found the definition of humanity. We become most fundamentally "generators of new descriptions" of reality, descriptions that are not ultimately "commensurable": They cannot be compared or evaluated because no one description can claim the privilege that would identify it as a measure. R. RoRTY, supra note 4 , at 378. The Critical echo of this is, of course, the conviction that if freed from the idea that a particular structure is standard, humans can create an infinite number of social and legal structures.

45. See supra text accompanying notes 31-37.

46. A continuing debate between Habermas and Hans-Georg Gadamer has made clear that the concept of selectivity introduced here critically alters Habermas' theory and that Habermas would object to the alteration. Both men start from agreement concerning the importance of our contextuality-our location in a certain community at a certain time-in forming our concept of reality. Habermas contends that once we realize our contextuality, and thus understand that our construction 
according to Unger's deviationist doctrine, ${ }^{47}$ can never be other than partial and particular-though they can indeed claim to be this somewhat more humble type of truth. ${ }^{48}$

Second, realization of the incompleteness of our vision explodes the insular potential of communicative theory. It is those whose situations are most different from our own who can illuminate most effectually our areas of blindness; therefore it is those who are most different whom we must be certain to include in our dialogue.

\section{B. Objectification}

With the acceptance of a subject whose understanding of the world and the self is developed through dialogue and dependent on, as well as limited by, contextuality, it becomes ever more necessary to examine objectification. The pervasive and stubborn tendency may reveal something of its author, an agent who becomes ever more important with the loss of "objectivity," or rather, with its rediagnosis as a reality humanly defined.

\section{Locating Objectification}

Habermas posits that the objective, social, and subjective spheres which constitute our worlds all consist of understandings negotiated according to "communicative rationality," a process procedurally similar in each case.

of reality is shot through with certain prejudices, those prejudices cease to convince us. See T. McCARTHY, supra note 30, at 182. Habermas' faith in this illuminating power of critical reflection is based on his belief that language can completely express even our "inner-natures" and that all linguistically-made claims can then be fully assessed, and accepted or rejected, according to our faculty of communicative rationality. Id. at 316 (quoting Habermas).

Gadamer argues instead that no amount of critical reflection can allow us to transcend our contexts in this way. As McCarthy explains:

The reflecting subject inevitably takes for granted a host of concepts, judgments, principles, and standards ... he cannot call everything into question all at once. Thus critique is necessarily partial and from a particular point of view. If the critical point of view is itself subjected to reflection, this is inevitably done from another point of view and on the basis of other takenfor-granted presuppositions.

Id. at 187. Gadamer asserts that it is only by striving to understand interpretations or articulations of reality different from our own that we can recognize the selectivity of our constructs and thus push outward, though never transcend, the bounds of our own contexts. The key is an openness to the beliefs of others and a preparedness to learn from them. Id. at 169-93 (excellent summary of Habermas-Gadamer debate).

47. Unger's "deviationist doctrine" is a form of internal critical development. One starts with conflicting ideals extant in society, imagines their flawed actualizations transformed (perhaps by being extended in application), and uses these hypothetical embodiments to revise the original ideals. Unger, supra note 3 , at $576-80$.

48. Unger recognizes such a limitation. He identifies both "[l]egal doctrine rightly understood and practiced" and normative argument generally as forms of internal critique described by deviationist doctrine. Id. at 580. See also M. Walzer, Tanner Lectures, Harv. Univ. (Nov. 13-14, 1985) (suggesting similar dynamic to characterize social criticism). The source of authority for claims in such contexts immediately becomes an issue: "Short of claiming access to authoritative revelation or privileged intuition," deviationist doctrine "lays claim to no privileged status capable of distinguishing it clearly from ideological dispute." Unger, supra note 3 , at $580,582$. 
Yet each sphere has a specific rationality that is substantively distinct, ${ }^{48}$ because the standard according to which claims in each sphere are evaluated varies. In the objective realm, where subject confronts object (e.g., scientific or empirical investigation), claims are made to truth or success. In the subjective realm, where subject expresses experiences (e.g., aesthetic expression), claims are to sincerity. And in the social realm, where subject interacts with subject (e.g., moral theory, law), claims are to rightness. ${ }^{50}$

According to Habermas, current mischaracterization of the way reality is organized-according to a subject/object dichotomy - has resulted in the misconceived notion that the rationality of the objective sphere is an appropriate way to evaluate claims made according to other standards as well. ${ }^{\text {s1 }}$ We "objectify" law when, overlooking the existence of the social sphere with its moral-practical rationality, we evaluate legal issues as if by objective standards.

Habermas' objection to conducting social reasoning (subject to subject) according to objective methods (subject confronting object) is convincing. However, Habermas succeeds in describing fully only the objective method, or "cognitive-instrumental rationality," according to which the subject has two relations to the world (representation and strategic action) and two standards by which to make and judge claims (truth and success). ${ }^{52}$ Moral-practical rationality and its standard of rightness are left

49. J. HABERMAS, supra note 26 , at 15 .

50. Id. at 15-22. In Habermas' terms, the reasoning faculties of the objective, social, and subjective realms are, respectively, "cognitive-instrumental rationality" (strategic action and representation), "moral-practical rationality" (moral, normative, or legal reasoning), and "aesthetic-practical discourse" (evaluation according to culturally-specific standards, thus not a form of assessment that merits the label "rationality").

51. See, e.g., id. at 239-42. See also McCarthy, Translator's Introduction to J. HaBermas, supra note 26 , at xxxvi-xxxvii.

52. Cognitive-instrumental rationality is given more explication and more emphasis from the very start of Habermas' book. It is the sub-type rationality through which Habermas describes the more general communicative rationality. J. HABERMAS, supra note 26 , at $8-22$. Within communicative action itself, strategic action (an operation of cognitive-instrumental rationality) is prominent relative to non-strategic, agreement-oriented speech. The human species is said to survive through sociallycoordinated activities, interventions coordinated through communication, but only "in certain central spheres through communication oriented to reaching agreement." Id. at 397 (emphasis added). Later, Habermas faults Weber for his contention that law can be legitimated only by procedure, arguing that this limitation of law to cognitive-instrumental rationality fails. Consensus still depends on normatively established limits. Id. at 264-71. But Habermas in turn asserts communicative rationality to be strictly procedural. Id. at 249. If it is, it may suffice to explain its subset in type, cognitiveinstrumental rationality, but it is questionable whether it can suffice to explain moral-practical rationality any more than Weber's rationality could explain law. Habermas also proposes that society needs "switching stations" at which individuals can switch from one complex of rationality to another. Id. at 250. But is is unclear what these switching stations are, or how the logics of the different spheres do in fact integrate. Perhaps we need to wait for Habermas' explanation of systems theory. But meanwhile we are left with the example of how cognitive-instrumental rationality alone operates, the subsystems in which it alone is institutionalized (e.g., economics, science), and the progress it alone has demonstrated. 
vague, and with their overtones of universality, ${ }^{53}$ are insufficiently distinguished from their objective counterparts. The fact of the mismeasurement remains, however, located by Habermas as the problem presented by legal reasoning.

\section{Admitting Objectification}

The complementarity identified above between Habermas' theory and the Heideggerian approach presages the development that may be made by exploring the latter's perspective on the problem of objectification. The notion that language is a dynamic, selective, and influential operation rather than merely a descriptive device correlates with an analogous model of rationality. The same dynamism and selectivity that enable linguistic expression also characterize thinking, Heidegger's "revealing." Jus Just as man cannot articulate reality fully, neither does he "find it," complete and detached. Rather, man as thinker forms and is in turn formed by the reality he tries to understand. However, as with language, he forgets the dynamic nature of this operation. He perceives thinking to be only an instrument-the tool of man, the Subject, acting in and on his world, the Object.

The implications suggested by this model of thought are significant: The strategic use of thought (its use as an instrument) leads to the objectification of that human process - the treatment of thought as a detached, objective, reasoning function. According to Heidegger, the apprehension is inevitable, ${ }^{\mathrm{ss}}$ and formative thinkers of the Frankfurt School, Max Horkheimer and Theodor Adorno, agree. They can suggest no form of thought, save artistic expression, that can escape objectification. ${ }^{58}$ It is against their despair that Habermas reacts when he maintains that the effect may be avoided by using the rationality of the objective sphere only where appropriate-in science, not in law. ${ }^{57}$ The persuasive power of Habermas' theory flags here, however, with its failure to distinguish adequately the method of rationality to be used in the social sphere. ${ }^{68}$ It is indeed more convincing that the faultline runs deeper: Objectification will occur whenever reason is used as a tool by subjects to regulate the world

53. See, e.g., T. MCCARTHY, supra note 30, at 313-17, 325-33 (reviewing and commenting on this characteristic in Habermas' theory).

54. For further explanation of the ideas summarized here, see M. HeIDEGGER, supra note 37, at 62-63, 135-46, 188-200.

55. See M. HEIDEGGER, supra note 37 , at $187-96$.

56. See J. HABERMAS, supra note 26, at 378-86 (summarizing views of Horkheimer and Adorno on this point).

57. See id. at 345-99 (relating views of Horkheimer and Adorno to theory of communicative action).

58. See supra note 52 . 
around them. Such a conclusion most obviously implicates law. If we are not to despair, nor escape here to a discussion of art, we must learn to deal with the phenomenon of objectification.

\section{Law as Language}

The debate between deconstructors and defenders of law can be retold using the theories set forth above. But translation into the new terms does not simply replicate the legal discussion, it recasts that discussion, leaving distinctive implications. These implications can be reintegrated into and thus affect the legal debate.

\section{A. The Translation: Law as the Language of Power}

Critical scholars have insisted that we recognize law as a specific set of decisions about the way societal relations should be organized rather than as an abstract ordering principle immanent in the relations of autonomous individuals. Law gains a kind of monopolistic momentum: It is used to bring about a certain organization, and is thereafter validated as standard according to the order it itself has defined. To put it in the terms used in Section II, a certain view of reality is communicatively constructed through law. Though the view is selective, by its articulation it is accepted as the real, the objective, because the articulation itself has delineated and restricted the reality according to which the view is evaluated.

Law-the effort of humans to create a social order-becomes distinct from its creators as it gains content with the articulation and realization of that order. The separation is an inevitable product of the acquisition of content, and the acquisition is equally necessary if the law is to fulfill its central purpose-to accomplish social coordination by affecting humans. Because law is so obviously an instrument, individuals lose sight of the fact that it is also a subjective and creative process, itself constituent of the order that it seeks to achieve. We ignore the agency of law, conceptualizing law simply as an object. Law becomes, to take a non-random example, the elaborate expression of a social contract.

Restoring a formative and dynamic nature to law mandates an alternative conception of law. It requires law to be understood as the continuing articulation of social order, a language itself, the language of power ${ }^{59}$ It is the medium that seeks to translate power-of kinds random and fre-

59. It is important to stress that I am not talking here about the "language of law," either in the sense used by Jerome Frank and others who focus on the legalistic terminology of law, or in the sense of the recent debate concerning legal and literary interpretation. For these topics, see respectively, e.g., J. Frank, supra note 3, at 24-34; Fiss, supra note 3; Symposium: Law and Literature, 60 TEX. L. REV. 373 (1982). 
quently conflicting, destructive of social relations-into a certain order. And it is the medium itself enabled by power- "the power of decision" to define the appropriate order and the power necessary to enforce that decision..$^{60}$

Conceptualizing law as such a language does not succeed in removing it from objectification. ${ }^{61}$ The law remains an instrument, but it is a medium rather than a thing (e.g., a legal "structure," "framework," or "system"). The difference is a substantial one, as a contrast with the classical liberal approach reveals.

In A Theory of Justice, John Rawls accomplishes a powerful revision of the social contract theory set forth by Locke, Kant, and Rousseau ${ }^{62}$ His aim is to identify those principles of justice to which rational beings, gathered behind a "veil of ignorance" as to their eventual interests, identities, and endowments in society, would reasonably agree. ${ }^{63}$ Specifically, Rawls delineates two principles, those of equality and difference, ${ }^{84}$ around which he develops his theory.

That the ordering principle of a society is, ought to be, or can be analogized to a contract between autonomous and abstract rational beings is obviously incompatible with the approach focused on articulation-in language, thought, or law-developed above. Locating Habermas' communicative rationality within the individual humanized the operation, giving it both blinders and vision: The essential point of Heidegger's insight is that human rationality is both possible and selective precisely because it is situated. When Rawls dislocates rationality from any context of community and history, he loses it, depersonalizing rather than purifying it. The result, predicts the law-as-language approach, will be a system powerful in theory with far from universal resonance in practice.

But if it is incompatible with Rawls' contract theory as described in $A$ Theory of Justice, the concept of law-as-language must fully acknowledge contract theory to be a profound expression of a specific society's legal culture. It is significant that in his most recent work, ${ }^{68}$ Rawls has retrenched his position to precisely such a stance. He cedes any claim that

60. Although definitions of law vary as widely as the scholars who have created them, law is generally agreed to include a coercive element, the threat or fact of physical or other force. See, e.g., E. Hogbel, The Law of Primitive Man: A Study in Comparative Legal. Dynamics 26 (1954); S. Moore, Law as Process: AN ANThropological Approach 10 (1978). A language of social coordination, minus the coercive element, seems a workable description of morality or ethics. See S. Hampshire, Morality and Conflict 135-37 (1983).

61. But see R. Rorty, Science as Solidarity 10 (Dec. 13, 1984) (paper presented at Legal Theory Workshop, Yale Law School). Rorty argues that we should simply "drop" objectification, a demand that the analysis offered here suggests is unrealistic.

62. J. RAWLS, A ThEORY OF JUSTICE 11 (1971).

63. Id. at 12 .

64. Id. at 14-15.

65. Rawls, Justice as Fairness: Political Not Metaphysical, 14 PHIL. \& PuB. Afr. 223 (1985). 
his contract theory is founded on an abstract notion of rationality, ${ }^{66}$ identifying as its basis instead "intuitive ideas" undeniably present in our culture, the most basic of which is a conception of society as a fair system of cooperation between free and equal persons. ${ }^{67}$ Rawls accepts certain implications that follow from his position: ${ }^{: 8}$ first, that social contract theory thus conceived may have little power over someone from another culture; and second, that beyond our borders, the application of the theory is ambiguous. ${ }^{69}$ In terms of the law-conceived-as-language, Rawls is himself identifying social contract theory as a powerful vocabulary in our particular language of law.

\section{B. The Implications of the Law-as-Language}

Agreement with Rawls' identification does not make possible a simple return to a one-dimensional concept of law as an object. Rather, it makes necessary an examination of the implications inherent in the notion of law as a complex medium of power. Like language, law is admitted to be communicatively constructed, selective, and systematically self-validating: It must therefore be treated in a manner commensurate with these characteristics. And like language, law is vulnerable to a test: Only as long as it can express human needs as humans define them does any language remain adequate, any language of power remain legitimate.

I propose to measure our current vocabulary of law according to these two propositions, the second of which seems the natural starting point. How does liberal legality as a vocabulary rate in the social structure we currently define and inhabit? That is, how successful is it in articulating a social order compatible with the conditions of society and community we presently construe? And, if current vocabulary is found to be inadequate, how should our language change?

\section{The Adequacy of the Liberal Vocabulary}

Dennis Pirages posits that a profound transformation affecting economic, political, ethical, and ecological outlooks is occurring worldwide. For the first time, the limits of the globe have been reached; it has become clear that its resources are finite and its inhabitants interdependent. ${ }^{70}$

\footnotetext{
66. Id. at 225 .

67. Id. at $230-31$.

68. These implications have been noted explicitly by Rawls. See Lecture by J. Rawls, Harv. Univ. (Oct. 15, 1985); see also Rawls, supra note 65, at 225.

69. According to Rawls, application of his theory appears to indicate not so much some kind of world government as a vision of an independent nation-state able to coexist peacefully with other democratic states. Lecture by $\mathrm{J}$. Rawls, supra note 68 .

70. D. Pirages, The New Context for International Relations: Global Ecopolitics 30 (1978).
} 
Pirages' message stands out only for its emphatic tone: In the fields of political science and economics it is commonly perceived that the era of insularity between nations is over. ${ }^{71}$ Most theories of psychology and sociology refute the notion that such an era ever existed for individuals. ${ }^{72}$ And events appear to indicate that a model of autonomy no longer answers in law.

I refer to the crisis that seems increasingly to deepen for liberalism. The crisis is at least one of faith: In our culture it is manifest in Legal Realism and in the Critical Legal Studies movement. It appears also to be one in fact: the rise of the welfare state; the development of legal theories that balance individual interests against values such as group parity and public debate $;^{73}$ court cases that mandate forced busing $;^{74}$ the confusion that the issue of affirmative action inspires; ${ }^{75}$ the retrenchment by Rawls of his theory of justice ${ }^{78}$ - these functionally deny the adequacy of a traditional liberal ideology. Such ideology surely has its defenders in politics, the academy, and the courts. But the continuing controversy itself is an indicator that the liberal vocabulary no longer adequately expresses circumstances in our world.

The controversy also reveals popular attitudes towards remedying the insufficiency, for a group can change its language in several ways. First, it can shift to a completely different tongue. ${ }^{77}$ Such a switch might be effected in the language that is law by a revolution and the establishment of a wholly new societal order. ${ }^{78}$ Second, a group can force its language to expand, by requiring it to express previously neglected interpretations of

71. For a poetic description of the newly discovered limits of the globe, see H. ARENDT, supra note 25, at 250. For a more pragmatic commentary, see WorLd DEv. REP. 1985, at iii, 169-229.

72. For a study that makes the point of our interdependence in an especially accessible way, see E. Goffman, The Presentation of Self in Everyday Life (1959).

73. E.g., Fiss, Groups and the Equal Protection Clause, 5 PhIL. \& Pub. AFf. 107 (1976); Fiss, Free Speech and Social Structure, U. Iowa L. REv. (forthcoming).

74. E.g., Morgan v. Kerrigan, 401 F. Supp. 216 (D. Mass. 1975), affd, 530 F.2d 401 (1st Cir. 1976), cert. denied, 426 U.S. 935 (1976).

75. See, e.g., Regents of Univ. of Cal. v. Bakke, 438 U.S. 265 (1978) (plurality opinion striking for its lack of clarity); M. SANDEL, supra note 23, at 135-47 (noting unfounded assumptions and inconsistencies in argument for affirmative action suggested by $\mathbf{R}$. Dworkin).

76. See supra text accompanying notes 65-69. The retrenched theory itself raises problems. For example, Rawls' vision of independent nation-states coexisting peacefully with democratic counterparts, see supra note 69 , is strikingly remote from our current reality-a dynamic of financial, political, military, and material interdependency in which the United States has never been a neutral agent.

77. Gadamer would argue that even the adoption of a new language could be made only from the reference point of the old. That is, the paradigm for the shift is one of translation, rather than one of primary socialization. See supra note 46; see also T. MCCARTHY, supra note 30, at 171-74 (reviewing Gadamer's argument).

78. The ideology of the American Revolution would appear to bear Gadamer out on his point, see supra notes $46 \& 77$, that deliberate rejection and transformation is made according to existing reference points: The colonists insisted that rights embodied in the British constitution justified their rebellion against Britain. See G. WoOd, The CReation of the American Republic, 1776 1787 , at 12 (1969). 
reality. ${ }^{79}$ The first type of change would involve a wholesale repudiation of our current law, a commitment widely belied by the continued presence of the system's detractors, lay and legal, within the community. Advocacy of radically new beginnings is rare compared to talk of radical transformation. ${ }^{80} \mathrm{~A}$ claim that the total population has been pacified by liberal ideology is conceivable but unconvincing. It seems more realistic to read popular reaction this way: Our law proved itself capable in the past of extending to meet new situations (when we willed it); it may contain the potential to continue that development. That is, the fact that liberalism gave us a medium rich enough to create a social order of immense value suggests that it may be possible and more constructive to expand that medium than to abandon it. ${ }^{81}$

\section{The Possibility and Places for Change in the Liberal Vocabulary}

This possibility returns us to the first proposition about law-aslanguage set forth above, that law be treated in a manner commensurate with its characteristics as a medium. ${ }^{82}$ We can evaluate whether our legal vocabulary does in fact have capacity for change, by examining whether our law admits and builds on the characteristics that distinguish language and allow it to grow. Specifically, we need to consider law according to the aspects of language delineated in Section II: To what extent are contributions sought to the continuing enterprise of the law's communicative construction; to what extent is the selectivity of the construction recognized and how is this selectivity dealt with; and in what manner and degree is the objectification of the final construction acknowledged? The questions yield a varying and revealing record.

\section{a. Contributions to the Construction of Law}

The right to participate or to contribute is a claim institutionalized within our current legal structure. While a reality of general participation remains to be realized, the ideal of this achievement is undoubtedly a central tenet. To further that end, our system of checks and balances, theories about process democracy, exaltation of free speech, and rights to represen-

79. See supra note 46 for a comparison between the development that can be achieved through critical reflection and that enabled by interpretation of visions foreign to us. Although the two are not mutually exclusive, it is only the second that reliably confronts us with the selectivity of our previous thought: "Seriously to study another way of life is necessarily to seek to extend our own." T. MCCarTHY, supra note 30 , at 181 (quoting P. Winch).

80. E.g., Unger, supra note 3 , at $580,672-73$. Unger's project is to create a system in which radical revolution can be accomplished through transformation. Id. at 670 .

81. Unger advocates "push[ing] the liberal premises about state and society," in order to reach a "superliberalism." Unger, supra note 3, at 602.

82. See supra p. 983. 
tation before an independent judiciary were designed and a civil war fought. That the participation ideal has been propagated within a liberal framework does not make its results incompatible with a more intersubjective model: Progress made in facilitating contributions to law is legitimate progress, whether made by beings who believe themselves autonomous or interdependent. For example, the "rights doctrine," a notion rejected as a pacifying sham by some Critical scholars, ${ }^{83}$ is a notion potentially as suited to recognizing the unique visions of interdependent subjects as to guarding the autonomy of each individual. ${ }^{84}$ In short, the importance of contribution is a theme articulated early in the American experience and established as central since that time.

\section{b. The Responsibility of Receptivity}

As discussed above, and as demonstrated by our own history, the communicative construction of a "real" order, of objects or of human relations, has an insular potential. But while the walls of language are generally quite permeable, those built by law are topped with barbed wire. The overcoming of the insular potential they contain comes only with the recognition of the selectivity of construction they represent. To be effective, the recognition must be made by those in power, while they are in power. ${ }^{85}$ If the law is to be responsive to all it affects (an aim explicit in rationales justifying the right to contribute), it is the powerful who have the responsibility to be receptive ${ }^{88}$ towards the views of those dissimilarly situated. ${ }^{87}$ Paradoxically, liberalism recognizes the essence of the obliga-

83. E.g., Klare, Labor Law as Ideology: Toward a New Historiography of Collective Bargaining Law, 4 InDus. Rel. L.J. 450, 468-82 (1981). But see Gabel \& Kennedy, supra note 4, at 26-36 (recognizing progress achieved by rights doctrine). For a defense of rights doctrine, see Sparer, supra note 3.

84. See Unger, supra note 3, at 597-600 (proposing rights doctrine retailored to fit interdependent subjects).

85. Recognition of selectivity is advocated here as a responsibility that attaches to power. Such recognition does not, therefore, equate with the resolve, also beneficial, to distribute or rotate power regularly, the aim at the heart of the right to contribute.

86. Phillip Johnson is correct when he notes the importance of "tolerance" in our liberal system. Johnson, supra note 2 , at 277 . Tolerance is necessarily the flip-side of a right to contribute. "Tolerance," however, is not synonymous with "receptivity," the value of affirmatively seeking to understand another's point of view. As Johnson defines it, tolerance connotes open-mindedness and respect for another point of view-but "not necessarily equal respect." Id. (emphasis in original). It is clearly not a challenge to the insularity of our individuality.

87. This is not to suppose that the less powerful are undoubtedly the more virtuous, and therefore do not have an obligation to listen to the views of others. Rather, the less powerful (within this group I include all who must in large part repress their interpretations of reality) cannot avoid listening to the dominant views in society, or, if the views of the dissidents and the conventions affirmed by the community are mutually exclusive, in society's jails. See Barkun, Law and Social Revolution: Millenarianism and the Legal System, 6 LAw \& Soc'y REv. 113, 126-27 (1971) (analyzing powerful socializing effect community exerts on nonconformist members). 
tion while denying its implications, for fully to admit the duty would be to undermine its sanctification of autonomy.

Listening to competing constructions of reality and of law is a guiding duty of our judiciary. ${ }^{88}$ It is a receptivity institutionalized, a receptivity that nevertheless achieves the human contact which is its real purpose. As Hoebel writes, "[a]n 'office' although culturally defined is, after all, exercised by an individual. . . . Power defined through allocation of legal authority is by its nature transpersonalized, yet by the nature of men it can never be wholly depersonalized." 89 Nor would liberal legality want it to be: Our system must recognize as a direct effect of that human element the success of the law in adapting, or in being adapted, to a changing society. ${ }^{90}$ Subsequent to a "hearing" of different views--which it is the lawyers' role to articulate as persuasively as possible-the judge selects one alternative, thus constituting, amplifying or eroding a specific order. Adjudication is thus formative: Like language, law is kept vital by its confrontation with different views; it is built by the decisions that ensue. ${ }^{91}$

In light of the primacy of this personal operation in liberal legality, that theory's denial of the element is striking. The official line is, of course, that the judges find, rather than make law. Although most now reject the response as a fiction, those who go so far as to emphasize the human element for the random or systematic biases it introduces continue to find mainstream response tepid at best and icy at times. ${ }^{82}$

If the fiction is in fact generally recognized as precisely that, it represents a needless incongruity between our present beliefs and our legal vocabulary. What would happen if we recognized both the value of the human receptivity offered by the judiciary-that "hearings" do take place-and the limitations of that receptivity-that subjectivity is also bias?

The behavior of the bench would remain "principled," according to our practice, as indeed it must if it is to remain persuasive. The bench is neither constrained nor legitimated by the fiction, but by something more profound, by the going enterprise itself, the commitment of the commu-

88. Like the right to contribute, it is an ideal far from realized. Nevertheless, that it is an explicit commitment is the significant point here.

89. E. HOEBEL, supra note 60 , at $277-78$.

90. See, e.g., G. Calabresi, A Common Law for the Age of Statutes 3-5 (1982) (on role of common law tradition in particular); A. PaUl, Conservative Grisis and the Rule of Law (1976) (documenting judicial development of "laissez-faire constitutionalism").

91. For a rich development of the dynamic described here, see Cover, Forward: Nomos and Narrative, 97 HARv. L. REv. 4 (1982).

92. See, e.g., Carrington, Of Law and the River, 34 J. Legal EDuc. 222 (1984) (recommending that those radically critical of legal system withdraw from teaching law); Martin, "Of Law and the River," and of Nihilism and Academic Freedom, 35 J. LEgal Evuc. 1 (1985) (responses to Carrington suggestion); J. FRANK, supra note 3, at viii-xxxi (Preface to Sixth Printing, responding to critical reactions accumulated during 18 years since publication). 
nity. Whether the judge wants to change or to conserve the language of power spoken by a society, he or she will use it to communicate. It is a common tongue that evokes agreement and produces effect, while alien approaches provoke misunderstanding, ridicule, reversal, official censure, widespread noncompliance, ${ }^{93}$ or lack of support from other branches. ${ }^{94}$ Indeed the judge is not chosen, in either a hierarchical polity or an egalitarian one, unless he or she has demonstrated a "know-how" of the current legal medium and a level of commitment to it. ${ }^{95}$ Rejecting the official fiction would not give free rein to power, but could add responsibility to its exercise: If the judicial voice is recognized as formative, the obligation of judicial receptivity due from the state and its officers becomes emphatic. At the level of ideals, perhaps the most effective but most elusive level, the affirmative responsibility of receptivity could become as much stressed as the right to counsel and a hearing. At a more practical level, recognition would encourage the offering of new and creative arguments made on the assumption that the legal vocabulary could expand. It would validate the demystification and healthy scrutiny of court decisions. It could lead to creative efforts to use the human element of the judiciary to good effect in combatting the dangers that accompany the impersonality of a growing government. ${ }^{98}$ Finally, awareness of that human element, while confirming the right of a community to require that its decision-makers be conversant in and committed to its continuing effort, would reveal as seriously handicapped and handicapping a bench that did not reflect the heterogeneity of its community.

The judiciary provides a vital function in our system, one our vocabulary should explicate rather than render enigmatic. But power is not limited to those who interpret the law; it is articulated also by those who draft and enforce it. It thus becomes significant, both symbolically and practically, that while we preserve the right of contribution for each indi-

93. The "all deliberate speed" qualification to forced desegregation is an example of a measure used to mediate a controversial court decision and so lessen noncompliance. See Fiss, supra note 3, at 760-61.

94. Id. at 758 (noting that President Eisenhower's hesitation in deploying federal troops in Little Rock raised possibility of lack of executive support).

95. See Fish, Fish v. Fiss, 36 STAN. L. REv. 1325 (1984) (arguing that interpretation is not constrained by external rules but is informed by assumptions and categories of understanding inherent to context and practice). While I agree with Fish's "conventionalist" account of interpretation, my conclusion that an obligation of receptivity follows from a recognition of our own contextuality is obviously at odds with his assertion that no implications for practice follow from such an understanding. Panel Discussion with Stanley Fish at Assoc. of Am. Law Schools seminar in San Francisco, Cal. (Jan. 7, 1984) (available on AALS Audiostats Tape 56, "Law and the Humanities" series).

96. See, e.g., G. CAlabresI, supra note 90 (suggesting that courts be given power to decide whether retentionist or revisionist bias should apply to statutory as well as common law rules). 
vidual, we institutionalize the responsibility of receptivity in just one office. ${ }^{97}$

If the creation of law is a communicative process, then the state as a whole functions as a crucible for the enterprise. Here power is localized, concentrated in the human agency that designs, enacts, and enforces the law. Here at every point when power and law are human should they be challenged with the human perspectives of those absent.

Beginning once again at the most ambitious level, an internal shift to an ideal of receptivity would make complacency and self-righteousness as distressing behaviors as we proclaim violence to be: All are barriers to real communication. On the more tangible level, ${ }^{98}$ the state itself would focus on the need to build receptivity into its infrastructure-the need to stimulate its personnel to listen actively. For example, although no longer so interpreted, ${ }^{90}$ the right to petition originally included a duty of legislative response. ${ }^{100}$ Attention to receptivity would imply a re-evaluation of this duty to see if it could be made administratively practicable. As another strategy, the tasks of designing and administering rules could be paired with forms of feedback, such as interviewing, that would connect the individual actualizing the law with those the law affects. Or we could simply include within the jobs of those who make and enforce our laws a blatant but perhaps effective investment aimed at increasing receptivity-a duty to some regular exposure, some involving human contact, with those it would not otherwise be within obligation or self-interest to encounter. Such designs would not be unrelated to the plea, frequently expressed but seldom defined, that we humanize the state and its bureaucracy. ${ }^{101}$

97. There is evidence that the responsibility has not always been so confined. Apparently, the right to petition was originally interpreted to include a guaranteed response from the legislature. See infra note 100. Political representatives are obviously still obligated to listen to their constituents. That duty enables views to be expressed in political debate, and as such is an essential way in which the right to contribute is institutionalized. See supra p. 985-86. By virtue of this purpose, and in order to secure reelection, the representative generally emphasizes the dominant views of his or her community. The extent to which his or her representative function ensures receptivity towards unpopular, alien, or obscure views is therefore minimal. See also J. ELY, supra note 31, at 77-101 (discussing problem of underrepresentation of minority members).

98. To the following suggestions, it might be appropriate to add Unger's "destabilization rights": "claims to the disruption of established institutions and forms of social practice that have achieved the very sort of insulation and have contributed to the very kind of crystallized plan of social hierarchy and division that the entire constitution wants to avoid." Unger, supra note 3, at 600 . Such rights, in theory, have the same goal as the suggestions presented here: All aim to challenge state indifference to those without power. However, I am not yet clear about how destabilization rights would look in practice. More importantly, the thrust of my argument here is that it is necessary to require more from those with power rather than to rely only on rights given to those without it, a group frequently disempowered from exercising rights they officially hold.

99. See Minnesota St. Bd. for Community Colleges v. Knight, 465 U.S. 271 (1984) (right to petition does not include guaranteed legislative response).

100. See R. Bailey, Popular Influence Upon Public Policy: Petitioning in EightEENTH-CENTURY VIRGINIA 55, 166-69, 174 (1979).

101. It may also be related to another frequently advocated goal, the revival of an ethic of involved 


\section{c. Objectification of the Law}

Recognition of the selectivity of law and the responsibility of receptivity that follows occupy an ambiguous place in American ideology because they conflict with an idea of an individuality that is autonomous. A similar dynamic influences the objectification of law.

As we have seen, the assumption that each member of society is an independent agent endowed with some kind of acontextual rationality leads to a notion of law as the codification of a social contract or as an objective, neutral, and determinant body of principles. Such a notion is becoming increasingly difficult to maintain. It presents an incongruity of vocabulary and belief similar to others noted above. What would be the result if we admitted that we do not believe it anymore?

Law would be examined as a creative process. Its rationales would be vulnerable to the criticism that they did not respond to human needs and conditions. In other words, legal argument probably would not change much, since we have treated it as a supremely human medium all along. ${ }^{102}$

The admission would seem to affect more conspicuously those speaking the language. The medium would clearly be their medium, notwithstanding the possibility that it developed haphazardly, by contingencies, influenced as much by disparate contributions as by a coherent plan. The areas emphasized-the degree to which special vocabularies were developed and intricacies explored-would remain profoundly their responsibility.

Recognition of this responsibility undermines one of the most well-worn axioms in our legal system today-that its operators are neutral actors. The recognition implies instead that each actor, by choosing his or her role, contributing human resources, and concentrating physical resources, affirms a certain portion of the arrangement. Elaboration or atrophy of each area within the construction are as determinative of its final shape as was its initial design.

The realization that objectivity is a status bestowed by us has a second consequence, one which affects not only those facile in the speech of law, but all under the law's jurisdiction. It reveals that the life of the law, its legitimacy, is not established by a hypothetical contract or an equally hypothetical consensus. It is achieved by remaining a common tongue recognized by various members as sufficiently their own that they will struggle with it and within it, rather than reject it by force, flight, or withdrawal. Legitimacy is thus always an active and cumulative quantity: If won not at all there will be mass societal revolution; if won at deep levels there 
will be only small rebellions, expressed on the surface of society as conflicts of interpretation. Legitimacy is thus always, also, an aspiration.

\section{G. The Human Factor}

Liberalism gave us the vocabulary to articulate a vision for American society and the terms with which to work toward its achievement. To call that vision historic appropriately reflects its strength, but also implies its limitation. For we now inhabit and acknowledge another world, a world in which our inherited language must either expand or be rendered anachronistic. One of liberalism's greatest achievements may be the opportunity it gives us to change it.

I am not suggesting that liberal jurisprudence give up its values of liberty and equality-worthy ideals in anyone's vocabulary. Rather, I am arguing that we cannot reach for them from the ideas of autonomy and objectivity, as they have traditionally been defined. The recognition of intersubjectivity and objectification as elements inherent to our action in the social sphere reveals in a new way our responsibility in the dialogue and decision that are law. It allows us to admit the insights of deconstruction and to use them in a realistic way. It does not assert law to be rudderless or lost in relativity. Rather, it locates law in our humanity, gives it a voice, and asks it to answer. 